Revista

\title{
Multi-Ensayos
}

Vol. 5, $\mathrm{N}^{\circ} 10$

ISSN: 2412-3285

https://multiensayos.unan.edu.ni

DOI: https://doi.org/10.5377/multiensayos.v5i10.8877

\section{La Soberanía Nacional y el Sufragio Universal como derechos de difícil conquista en el devenir de la historia Constitucional}

\section{National Sovereignty and Universal Suffrage as rights of hard to conquer in the future of Constitutional history}

José Vicente Corrales Morales ${ }^{1}$

Recibido: 20 de mayo de 2019. Aceptado: 30 de junio de 2019

\section{RESUMEN}

Este ensayo es una recopilación histórica de las constituciones en menester de la Soberanía y el Sufragio Universal como derechos de difícil conquista y que ahora podemos gozar. Para lograr este cometido, hubo necesidad de ponerse inmerso en las diferentes Constituciones que Nicaragua ha tenido vigentes a largo de la historia, con el énfasis merecido de la soberanía, la independencia, la libertad, la democracia, el territorio sobre el cual se ejerce dicha soberanía, el ser nicaragüense, los derechos ciudadanos y en especial, el sufragio universal. Al final solo se relacionará en la parte conclusiva el efecto de dichas Constituciones en el contexto real de nuestra historia, donde se encuentra un contraste entre lo escrito en las Constituciones y lo sucedido realmente.

Palabras claves: soberanía; independencia; libertad; democracia; territorio; nacionalidad; ciudadanía.

\section{ABSTRACT}

This essay is a historical compilation of the constitutions in need of sovereignty and Universal suffrage as rights of difficult conquest and now we can enjoy. To achieve this task, there was a need to immerse yourself in the various constitutions that Nicaragua has had in force throughout history, with the deserved emphasis of sovereignty, independence, freedom, democracy, the territory on which It exerts such sovereignty, the Nicaraguan being, the citizens' rights and, in particular, the universal suffrage. In the end it will only be related in the conclusive part the effect of these constitutions in the real context of our history, where there is a contrast between the written in the constitutions and what actually happened.

Keywords: sovereignty, independence, freedom, democracy, territory, nationality, citizenship.

1 Docente UNAN-Managua/FAREM-Estelí. Correo electrónico: jvc2803@yahoo.com.

(c) 2019 Revista Multi-Ensayos.

(c) (i) (2) Este trabajo está licenciado bajo una Licencia Internacional Creative Commons 4.0 Atribución-NoComercial-Compartirlgual. 


\section{INTRODUCCIÓN}

La Constitución Política del Estado es la norma jurídica suprema positiva que rige la organización de un Estado, estableciendo: la autoridad, la forma de ejercicio de esa autoridad, los límites de los órganos públicos, definiendo los derechos y deberes fundamentales de los ciudadanos y garantizando la libertad política y civil del individuo.

El termino Constitución deriva del latín "cum", 'con', y "statuere", 'establecer'. Entonces se traduciría como "forma o manera de establecer las reglas de funcionamiento y distribución del Poder Público".

Una Constitución política es "un orden instituido por los ciudadanos de una polis con el fin de regular la distribución del poder" (Aristóteles, "De La Política", libro III).

En esta temática se analizarán las Constituciones más sobresalientes en el transcurso de la historia de Nicaragua en lo que se refiere a la Soberanía y el Sufragio Universal como derechos de difícil conquista en el devenir de la historia, donde se demostrará con contundencia cómo es que las y los Nicaragüenses gozamos a plenitud de estos derechos, lo cual se constituye, mediante los principios en que se basan las constituciones, el territorio sobre el que ejerce su soberanía y la calidad del ciudadano Nicaragüense.

\section{DESARROLLO}

La soberanía y el derecho al voto son derechos constitucionales que en estos tiempos se encuentran conquistados y disfrutados por las y los Nicaragüenses, que se han venido consolidando en el devenir de la historia con las luchas que ejercieron nuestros próceres de la patria pensando en una Nicaragua cada vez major, aunque los intereses egoístas del imperio se hicieron valer por mucho tiempo al final venció nuestra Nicaragua Libre.

Para desarrollar esta temática, se hace necesario de un riguroso studio de las Constituciones Vigentes en Nicaragua en la historia Constitucional, para lo cual se irá exponiendo en cada una de dichas Constituciones los Derechos que atañen a este estudio.

\section{Constitución de 1824}

De conformidad con la Constitución de 1824 en su arto. 1 refiere que Nicaragua estaba establecida como tipo de Estado Federal, cuando dice: El pueblo de la República federal de Centro América es soberano e independiente; $y$ en su arto. 8 expresa sobre el tipo de gobiermo y al respecto menciona: el gobierno de la República: es popular, representativo, federal; y en el Arto. 9 precisa que la República se denomina: Federación de Centro América.

En cuanto al territorio obre el cual se ejerció soberanía tenemos en el arto. 5 lo si siguiente: El territorio de la República es el mismo que antes comprendía el antiguo reyno de Guatemala, a excepción de la 
provincia de Chiapas; estableciendo así los Estados que componían esta Federación en el arto. 6 que dice: La federación se compone actualmente de cinco estados que son: Costarrica, Nicaragua, Honduras, el Salvador y Guatemala. La Provincia de Chiapas se tendrá por Estado en la Federación cuando libremente se una, y esto úñtimo sucedió alrevés.

\section{Constitución de 1826}

Acorde con la Constitución de 1826 en su arto. 4 declara siempre que Nicaragua estaba establecida como tipo de Estado Federal cuyo texto nos dice: el Estado es libre, soberano é independiente en su Gobierno y administración interior; y su soberanía e independencia se limitan por las restricciones establecidas a cada uno de los Estados, en la Constitución Federal de la República.

En el arto. 2 nos plantea que el territorio del Estado comprende los partidos de Nicaragua, Granada, Managua, Masaya, Matagalpa, Segovia, León, Subtiaba y el Realejo. Sus límites son: por el Este, el Mar de las Antillas: por el Norte, el Estado de Honduras: por el Oeste, el Golfo de Conchagua: por el Sur, el océano Pacífico; y por el Sudeste el Estado libre de Costarrica; que en el arto. 7 afirma que el pueblo del Estado ejerce su soberanía eligiendo sus primeros funcionarios, y concurriendo a la elección de las autoridades federales; todo del modo establecido por la Constitución general y la particular del mismo Estado.

En estas dos épocas se entendió que la Independencia de Centroamérica no trajo ningún beneficio para las grandes mayorías y el poder pasó a manos de los criollos que representaban a los grandes hacendados y comerciantes, que se oponían a brindar participación a los otros grupos sociales en el gobierno, al punto que dejaron intactas las estructuras económicas, jurídicas y sociales de los peninsulares.

\section{Constitución de 1838}

En consonancia con la Constitución de 1838 en el arto. 4 se entiende por Estado de la siguiente manera: El Estado es, y por derecho debe ser, cuerpo político, y como tal, es libre, soberano e independiente.

En el arto. 17 refiere la particularidad de ser nicaragüense, y así tenemos la misma concepción de la anterior constitución. Pero en cuanto al arto. 18 Nos da una categoría precise para ser ciudadano cuando expresa: Son ciudadanos todos los nicaragüenses naturales, o naturalizados, mayores de veinte años, o a los de diez y ocho que tengan algun grado científico, o sean casados, poseyendo ademas todos alguna propiedad, oficio o profesion de que subsistan, calificado conforme a la ley; el poder pasó a manos de los descendientes de los criollos, manteniendo el asunto de clases.

\section{Constitución de 1858}

\section{Según la Constitución de 1858}

Respecto al hecho de ser nicaragüense, tener ciudadanía y sus derechos los artos. 7, 8 y 9 refieren: Son nicaragüenses: Los oriundos de la República; Los que hayan adquirido aquella cualidad conforme a las 
leyes; y los hijos de aquéllos y de éstos habidos en país extranjero, si sus padres no hubiesen perdido la naturaleza de nicaragüenses. Lo serán también los que obtengan carta de naturaleza, los centroamericanos y los extranjeros que residan en la República por el tiempo que la ley determine y tengan las cualidades que ella señale; Arto. 8- Son ciudadanos: Los nicaragüenses mayores de veintiún años o de dieciocho que tengan algún grado científico o sean padres de familia, siendo de buena conducta y teniendo una propiedad que no baje de cien pesos o una industria o profesión que al año produzca lo equivalente; Arto. 9- Son derechos de los ciudadanos: 1. -Elegir las autoridades. 2.-Tener opción a los destinos, si profesando la religión de la República, reúnen las demás cualidades requeridas por la Constitución y la ley. En teoría estamos frente a la primera gran Democracia al denominarse por primera vez Nicaragua como República, sin embargo seguía la situación selectiva para optar a cargos públicos y ejercer el derecho al voto.

\section{Constitución de 1893}

\section{La Constitución de 1893}

En en el arto. 7 se hace referencia el ser Nicaragüense, y así tenemos la misma concepción de la anterior constitución, pero en el Arto. 20 amplía la concepción de ciudadanía y dice: Son ciudadanos todos los nicaragüenses mayores de dieciocho años, y los mayores de dieciséis que sean casados o que sepan leer y escribir; y en el arto. 21 expresa sobre los Derechos de los ciudadanos los cuales son: el sufragio, el optar a los cargos públicos y el tener y portar armas, todo con arreglo a la ley; en este momento de la historia se tiene por primera vez la posibilidad de considerar a todos los hombres como ciudadanos.

\section{Constitución de 1912}

El Arto $7^{\circ}$ nos habla de las mismas condiciones para ser nicaragüense que son naturales ó naturalizados; y el arto. 18 sobre los ciudadanos que son todos los nicaragüenses mayores de veintiún años, y los mayores de dieciocho que sean casados ó que sepan leer y escribir; y así el arto 19 expresa sobre los Derechos de los ciudadanos los cuales son: $1^{\circ}$. El sufragio $2^{\circ}$. El optar á los cargos públicos, y $3^{\circ}$. El tener y portar armas, todo con arreglo á la ley.

\section{Constitución de 1939}

Sobre los Ciudadanos Nicaragüenses tenemos los artos. 14 y 28 que se escribieron en los mismos términos de la constitución de 1912, y en cuanto a sus Derechos y Obligaciones los artos. 29 y 30 mencionan que son derechos del ciudadano: optar a los cargos públicos que lleven anexa autoridad o jurisdicción; reunirse, asociarse y hacer peticiones para fines políticos, todo con arreglo a la ley; Son obligaciones del ciudadano: 1) Inscribirse en los Registros o Catálogos Electorales. 2) Votar en las elecciones populares. 3) Desempeñar, salvo excusa o renuncia con causa, los cargos de elección popular y los concejales; 4) Prestar servicio militar y los demás que exija el Estado; En cuanto al voto activo, la ley determinará cuándo ha de ejercerlo, necesitándose para dictar disposiciones a este respecto, por lo menos, el voto de las tres cuartas partes de los miembros del Poder Legislativo. 


\section{Constitución de 1948}

La Constitución de 1948 consigna en su arto. 2 que el fundamento del territorio nacional es el uti possidetis juris (Posesión que procede conforme a Derecho) de 1821.

En cuanto las descripciones de ciudadanos nicaragüenses lo que se modifica se encuentra en el arto. 30 y estirpó el numeral 4) Prestar servicio militar y los demás que exija el Estado

\section{Constitución de 1950}

En cuanto los ciudadanos nicaragüenses el arto. 31 hace una inclusion sumamente interesante cuando menciona: Son ciudadanos los nicaragüenses varones y mujeres mayores de veintiún años de edad; los mayores de diez y ocho que sepan leer y escribir o sean casados; y los menores de diez y ocho que ostenten un título académico; lo que en el arto. 32 se determina que son derechos del ciudadano optar a los cargos públicos, reunirse, asociarse y hacer peticiones, todo con arreglo a la ley, en el cual la mujer puede ser elegida o nombrada para el ejercicio de cargos públicos, salvo los casos expresamente exceptuados por la Constitución; y más paricularmente el arto. 33 delimita cuáles son las obligaciones del ciudadano entre las que se enumeran: 1) Inscribirse en los Registros Electorales; 2) Votar en las elecciones populares. La mujer ejercerá el sufragio activo de acuerdo con la ley que se dicte sobre la materia, con el voto de las dos terceras partes de la totalidad de cada Cámara; 3) Desempeñar, salvo excusa calificada por la ley, los cargos concejiles. La ley reglamentará estas obligaciones y determinará las penas por su infracción.

\section{Constitución de 1974}

De conformidad con la Constitución de 1974 el Arto. 1 considera a Nicaragua como una nación constituida en Estado unitario, libre, soberano e independiente; que en correspondencia a ello el arto. 4 refiere que la soberanía del estado es absoluta e indelegable y, tanto como el territorio, indivisible, inalienable e imprescriptible; y en cuanto al gobierno el arto. 9 dice: El Gobierno del Estado es republicano y democrático representativo.

El arto. 3 determina que el territorio nacional se extiende, bajo la plena soberanía del Estado, entre lo Océanos Atlántico y Pacífico y las Repúblicas de Honduras y Costa Rica. Comprende además, en igual condición, las islas, los cayos, los morros, los bancos adyacentes, los zócalos submarinos, el mar territorial y la plataforma continental, así como el espacio aéreo, la estratosfera y todo el ámbito submarino que le corresponde en domino soberano, conforme el Derecho Internacional.

Aquí se establece el nacimiento del cuarto poder del Estado, El Poder Electoral, y en su arto. 10 lo menciona y dice: Son Órganos del Gobierno el Poder Legislativo, el Poder Ejecutivo, el Poder Judicial y el Poder Electoral. 
Sobre la ciudadanía el arto. 32 refiere: Son ciudadanos los nicaragüenses mayores de veintiún años de edad, los mayores de dieciocho que sepan leer y escribir o sean casados; y los menores de dieciocho que hayan concluido sus estudios de educación media.

\section{Constitución de 1987}

Según la Constitución de 1987 en su arto. 1 menciona sobre los derechos irrenunciables de la nación, así mismo, sobre el no injerencismo, y en correspondencia se refiere: La independencia, la soberanía y la autodeterminación nacional son derechos irrenunciables del pueblo y fundamentos de la nación nicaragüense. Toda injerencia extranjera en los asuntos internos de Nicaragua o cualquier intento de menoscabar esos derechos, atentan contra la vida del pueblo. Es derecho del pueblo y deber de todos los ciudadanos, preservar y defender con las armas en la mano si es preciso, la independencia de la patria, la soberanía y la autodeterminación nacional.

El arto. 2 establece el nexo más elemental entre la Soberanía Nacional y el Sufragio Universal, cuando refiere: La soberanía nacional reside en el pueblo, fuente de todo poder y forjador de su propio destino. El pueblo ejerce la democracia decidiendo y participando libremente en la construcción del sistema económico, político y social que más conviene a sus intereses. El poder lo ejerce el pueblo directamente y por medio de sus representantes libremente elegidos de acuerdo al sufragio universal, igual, directo, libre y secreto.

Y en el arto. 7 que Nicaragua es una república democrática, participativa y representativa. Son órganos de gobierno: El Poder Legislativo, el Poder Ejecutivo, el Poder Judicial y el Poder Electoral.

\section{Reformas Constitucionales de 2014}

De acuerdo con las Reformas Constitucionales de 2014 en su artículo 1. Refiere que la independencia, la soberanía y la autodeterminación nacional, son derechos irrenunciables del pueblo y fundamentos de la nación nicaragüense. Toda injerencia extranjera en los asuntos internos de Nicaragua o cualquier intento de menoscabar esos derechos, atenta contra la vida del pueblo. Es deber de todos los nicaragüenses preservar y defender estos derechos; así se renuncia a la idea de las armas que lo mencionaba la Constitución de 1987.

El arto. 2 establece el nexo, aún más elemental, entre la Soberanía Nacional y el Sufragio Universal, cuando refiere: La soberanía nacional reside en el pueblo y la ejerce a través de instrumentos democráticos decidiendo y participando libremente en la construcción y perfeccionamiento del sistema económico, político, cultural y social de la nación. El poder soberano lo ejerce el pueblo por medio de sus representantes libremente elegidos por sufragio universal, igual, directo y secreto, sin que ninguna otra persona o reunión de personas pueda arrogarse esta representación. También lo puede ejercer de forma directa a través del referéndum y el plebiscito. Asimismo, podrá ejercerlo a través de otros mecanismos directos, como los presupuestos participativos, las iniciativas ciudadanas, los Consejos territoriales, las asambleas 
territoriales y comunales de los pueblos originarios y afrodescendientes, los Consejos sectoriales, y otros procedimientos que se establezcan en la presente Constitución y las leyes.

En el arto. 6 se amplía el concepto de que Nicaragua es un Estado independiente, libre, soberano, unitario e indivisible. Se constituye en un Estado Democrático y Social de Derecho, que promueve como valores superiores la dignificación del pueblo a través de su ordenamiento jurídico, la libertad, la justicia, la igualdad, la solidaridad, la responsabilidad social y, en general, la preeminencia de los Derechos Humanos, la ética y el bien común. Las ciudadanas y ciudadanos y la familia son elementos protagónicos en la toma de decisiones, planificación y gestión de los asuntos públicos del Estado.

En el arto 7 se contempla que Nicaragua es una República democrática y se orienta esa democracia con el Sufragio Universal. La democracia se ejerce de forma directa, participativa, y representativa. Las funciones delegadas del Poder Soberano se manifiestan a través del Poder Legislativo, Poder Ejecutivo, Poder Judicial y Poder Electoral. Tienen funciones especializadas y separadas, colaborando armónicamente entre sí para la realización de sus fines. Existen otras instituciones y entes autónomos para el cumplimiento de funciones específicas del Estado. Siempre mantiene el reconocimiento de ser una nación multiétnica.

\section{CONCLUSIÓN}

Así es como se tiene regulado en el devenir de la histotria Constitucional la Soberanía y el Derecho al Sufragio Universal de las ciudadanas y los ciudadanos, sin embargo hay que apuntar elementos claves de la Historia que en Nicacaragua no se respetaron tal como se escribieron, como sería el caso de que la soberanía y la democracia recaía en manos de los Criollos y no de nuestros antepasados que quedaron libres pero sin muchos derechos durante las Constituciones de 1824, 1826 y 1838.

Así también, cómo se puede hablar de Democracia mientras nuestra gente erea sometido a toda clase de injustacia, explotación y maltrato, limitándolo a un asunto de clases durante la Constitución de 1858.

La libérrima de 1893 y sus reformas fue la primera evidencia de intento por conquistar para todos la igualdad, lo cual acercó, de alguna manera, la posibilidad de que los hombres contribuyeran a la democracia para elegir libremente según su decision, más dejaron fuera los derechos de las mujeres.

Cómo es possible hablar de República, Soberanía y Democracia cuando las votaciones eran manejadas y coacionadas por el Poder del Imperio de los Estados Unidos de América, al punto de invader nuestra nación, e imponer a las y los Nicaragüenses una dinastía de carácter hereditario como lo la dictadura Somocista.

Únicamente la Revolución Popular Sandinista fue la portadora de la verdadera Soberanía y Democracia, donde no se ha incluido a la mujer para votar, sino también, para optar a cargos públicos en igualdad con el hombre, con el Estatuto Fundamental de 1979 y las Constitución de 1987 y sus reformas actuales 2014, y en esta ultima en su arto. Artículo 131 que establece que para el caso de los funcionarios electos 
mediante el voto popular por listas cerradas propuestas por los partidos políticos bajo el principio de la proporcionalidad, Diputados ante la Asamblea Nacional, Diputados al Parlamento Centroamericano, Concejales Municipales, Concejales Regionales, las listas de candidatos deberán estar integrados por un cincuenta por ciento de hombres y un cincuenta por ciento de mujeres, ordenados de forma equitativa y presentados de forma alterna; igual relación de género deberán mantener entre propietarios y suplentes donde los hubiere, así manifestando y ejerciendo los Poderes reales de una República Libre e Independiente.

\section{REFERENCIAS}

Constitución de 1824, publicada en la ciudad de Guatemala el 22 de Noviembre de 1824.

Constitución de 1826, publicada en la ciudad de Leon, el 22 de abril de 1826.

Constitución de 1838, publicada en la ciudad de Leon, el 17 de noviembre de 1838

Constitución de 1858, publicada en la ciudad de Managua, el 19 de agosto de 1858

Constitución de 1893, publicada en la ciudad de Managua, el 10 de Diciembre de 1893

Constitución de 1912, Managua, publicada en La Gaceta Oficial No. 13 el 17 de Enero de 1912

Constitución de 1939, Managua, publicada en La Gaceta No. 68, del 23 de Marzo de 1939

Constitución de 1948, Managua, publicada en La Gaceta No. 16, de 22 de enero de 1948

Constitución de 1950, Managua, publicado en La Gaceta No. 235 del 06 de Noviembre de 1950

Constitución de 1974, Managua, publicado en La Gaceta No. 89 del 24 de Abril de 1974

Constitución de 1987, Managua, publicada en La Gaceta No. 05 del 09 de Enero de 1987

Reformas Constitucionales de 2014, Managua, publicada en La Gaceta No. 05 del 09 de Enero de 1987

INCER Barquero, Jaime y ROMERO Vargas, Germán. Estudios Sociales Cuarto Grado.

Managua: 2002

INCER Jaime y ROMERO Germán. Estudios Sociales: 3er. Grado: Geografía e Historia de

Nicaragua. Editorial HISPAMER. Managua, Nicaragua. 1998

Ministerio de Educación. Historia: 4to. Grado: así se ha forjado nuestra patria. Nicaragua.

1987

ROMERO, Germán. Historia de Nicaragua: Cuarto Grado. Nicaragua, 1991 